\title{
Deformation Mechanisms in Austenitic TRIP/TWIP Steel as a Function of Temperature
}

\author{
STEFAN MARTIN, STEFFEN WOLF, ULRICH MARTIN, LUTZ KRÜGER, \\ and DAVID RAFAJA
}

\begin{abstract}
A high-alloy austenitic CrMnNi steel was deformed at temperatures between $213 \mathrm{~K}$ and $473 \mathrm{~K}$ $\left(-60{ }^{\circ} \mathrm{C}\right.$ and $\left.200{ }^{\circ} \mathrm{C}\right)$ and the resulting microstructures were investigated. At low temperatures, the deformation was mainly accompanied by the direct martensitic transformation of $\gamma$-austenite to $\alpha^{\prime}$-martensite ( $\mathrm{fcc} \rightarrow \mathrm{bcc}$ ), whereas at ambient temperatures, the transformation via $\varepsilon$ martensite ( $\mathrm{fcc} \rightarrow \mathrm{hcp} \rightarrow \mathrm{bcc}$ ) was observed in deformation bands. Deformation twinning of the austenite became the dominant deformation mechanism at $373 \mathrm{~K}\left(100{ }^{\circ} \mathrm{C}\right)$, whereas the conventional dislocation glide represented the prevailing deformation mode at $473 \mathrm{~K}\left(200{ }^{\circ} \mathrm{C}\right)$. The change of the deformation mechanisms was attributed to the temperature dependence of both the driving force of the martensitic $\gamma \rightarrow \alpha^{\prime}$ transformation and the stacking fault energy of the austenite. The continuous transition between the $\varepsilon$-martensite formation and the twinning could be explained by different stacking fault arrangements on every second and on each successive $\{111\}$ austenite lattice plane, respectively, when the stacking fault energy increased. A continuous transition between the transformation-induced plasticity effect and the twinninginduced plasticity effect was observed with increasing deformation temperature. Whereas the formation of $\alpha^{\prime}$-martensite was mainly responsible for increased work hardening, the stacking fault configurations forming $\varepsilon$-martensite and twins induced additional elongation during tensile testing.
\end{abstract}

DOI: $10.1007 / \mathrm{s} 11661-014-2684-4$

(C) The Minerals, Metals \& Materials Society and ASM International 2014

\section{INTRODUCTION}

AustenitiC stainless steels are widely used in engineering applications because of their excellent formability in combination with high strength and corrosion resistance. In high-alloy austenitic steels, the addition of chromium, nickel, and manganese stabilizes the hightemperature austenitic phase of iron down to room temperature. Depending on the concentration of the alloying elements, the as-produced microstructure consists mainly of fcc- $\gamma$-austenite, although the bcc ferrite or $\alpha^{\prime}$-martensite and hcp- $\varepsilon$-martensite may occur. ${ }^{[1]}$ Furthermore, the austenite often remains in a metastable state and transforms martensitically under mechanical loading into the bcc or hcp state. Consequently, the mechanical properties are altered tremendously if a phase transformation occurs during plastic deformation. During the $\gamma \rightarrow \alpha^{\prime}$ or the $\gamma \rightarrow \varepsilon \rightarrow \alpha^{\prime}$ martensitic transformation, the transformation-induced plasticity (TRIP) effect is triggered, yielding higher elongation during tensile testing. ${ }^{[2]}$ By the formation of new interfaces

STEFAN MARTIN, Postdoc, and DAVID RAFAJA, Full Professor, are with the Institute of Materials Science, TU Bergakademie Freiberg, 09599 Freiberg, Germany. Contact e-mail: stefan.martin@ iww.tu-freiberg.de STEFFEN WOLF, formerly Postdoc, ULRICH MARTIN, Professor Emeritus, and LUTZ KRÜGER, Full Professor, are with the Institute of Materials Engineering, TU Bergakademie Freiberg, 09599 Freiberg, Germany.

Manuscript submitted August 8, 2014.

Article published online December 3, 2014 through the phase transformation, a pronounced workhardening effect occurs. ${ }^{[3]}$

The thermodynamic driving force for the $\alpha^{\prime}$-martensite formation is related to the difference of the Gibbs free energy between austenite and $\alpha^{\prime}$-martensite $\left(\Delta G^{\gamma \rightarrow \alpha^{\prime}}\right)$. Since the austenite represents the high-temperature phase, which is artificially stabilized by alloying, the driving force increases with decreasing temperature. For different $\mathrm{Ni}$ concentrations, $\Delta G^{\gamma \rightarrow \alpha^{\prime}}$ is plotted as a function of temperature in Figure 1(a) ${ }^{[4]}$ The graphs exhibit a linear form in which the alloy with the highest $\mathrm{Ni}$ concentration shows a negative $\Delta G^{\gamma \rightarrow \alpha^{\prime}}$ below approx. $313 \mathrm{~K}\left(40{ }^{\circ} \mathrm{C}\right)$. All other alloys with a lower Ni content exhibit a higher driving force for the $\alpha^{\prime}$-martensite formation. Furthermore, the martensitic transformation can be enhanced with the aid of mechanical stresses acting under plastic deformation, although the level of $\Delta G^{\gamma \rightarrow \alpha^{\prime}}$ is not high enough to compensate for the interfacial and strain energy during $\alpha^{\prime}$-martensite nucleation at the specific testing temperature. ${ }^{[5]}$ The value of the $\mathrm{M}_{\mathrm{d}}$ temperature indicates the temperature at which enough activation energy is provided by the deformation - in addition to the chemical driving force-to trigger the martensitic transformation.

Through the addition of the alloying elements, the difference between the Gibbs energy $\left(\Delta G^{\gamma \rightarrow \varepsilon}\right)$ of the fcc crystal lattice and the hcp crystal lattice becomes rather low as well..$^{[6,7]}$ This implies that the formation of stacking faults (SFs) in the fcc austenite lattice, which 


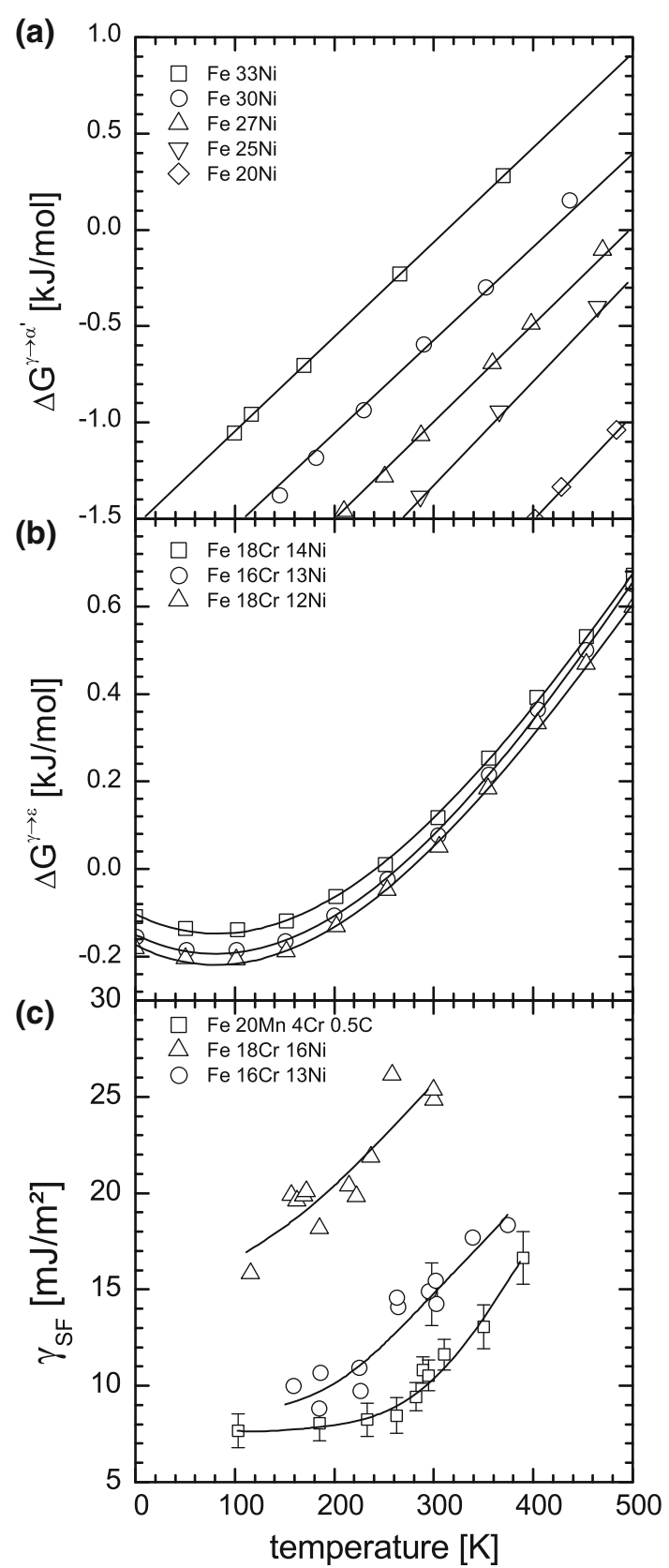

Fig. 1-Thermodynamic driving forces influencing the deformation behavior of high-alloy austenitic steels as a function of temperature: (a) difference of Gibbs energy for the martensitic transformations from austenite to $\alpha^{\prime}$-martensite for binary iron nickel alloys (data from Ref. [4]); $(b)$ difference of Gibbs energy for the martensitic transformations from austenite to $\varepsilon$-martensite for $\mathrm{CrNi}$ steels (data from Ref. [6]); and (c) the stacking fault energy of $\mathrm{CrMnNi}$ steels (data from Ref. [63]).

alters the $A B C A B C$ stacking sequence of the $\{111\}$ lattice planes into the hep $A B A B$ sequence, requires less energy than in pure fcc iron, which is expressed by a low stacking fault energy (SFE $\leq 50 \mathrm{~mJ} / \mathrm{m}^{2}$ ). ${ }^{[8]}$ According to the approach of Olson and Cohen, ${ }^{[6]}$ the SFE is defined by

$$
\gamma_{\mathrm{SF}}=n \rho\left(\Delta G^{\gamma \rightarrow \varepsilon}+E^{\mathrm{str}}\right)+2 \sigma(n)
$$

where $n$ is the number of faulted lattice planes and $\rho$ is the density of atoms per lattice plane. $E^{\text {str }}$ represents the elastic strain energy associated with the local fcc $\rightarrow$ hcp transformation, and $\sigma$ is the interfacial energy per unit area between the faulted volume and the non-faulted matrix. ${ }^{[9]}$ The applicability of this approach was discussed in detail by Geissler et al. ${ }^{[10]}$ If the influence of temperature is discussed (Figure 1(c)), the main influence is attributed to $\Delta G^{\gamma \rightarrow \varepsilon}$ (Figure 1(b)), whereas the other contributions show only a negligible temperature dependence. $^{[6]}$

With a low SFE, special deformation mechanisms in the austenite are activated that involves SF formation, ${ }^{[11-17]}$ namely single-slip $\varepsilon$-martensite formation and twinning. The dissociation width $\left(d_{\mathrm{s}}\right)$ of partial dislocations depends mainly on the shear stress component on the glide plane $\tau_{z x}$ and the SFE $\left(\gamma_{\mathrm{SF}}\right)$ according to Byun. ${ }^{[18]}$ Assuming an angle of $30 \mathrm{deg}$ between the Burgers vectors of each partial dislocation and the line vector of the perfect dislocation, $d_{\mathrm{s}}$ can be calculated as follows:

$$
d_{\mathrm{S}}=\frac{1}{8 \pi} \times \frac{2-3 v}{1-v} \times \frac{G b_{\mathrm{p}}^{2}}{\gamma_{\mathrm{SF}}-\tau_{z x} b_{\mathrm{p}} / 2} .
$$

Furthermore, the shear modulus $G$, Poisson's ratio $v$, and the magnitude of the Burgers vector of the partial dislocations $b_{\mathrm{p}}$ are included. The smaller the SFE and the larger the shear stress, the wider the dissociation of the partial dislocations.

In the case of a low SFE, dislocations dissociate into Shockley partial dislocations and, thus, the SFs are formed between the partials in the austenite. As cross slip of widely dissociated dislocations is omitted, the deformation via single-slip is observed for suitably oriented glide systems. Thus, conventional dislocation glide and the formation of dislocation cells are only observed on glide systems, where the trailing partial experiences a higher force than the leading partial. ${ }^{[19,20]}$ Plastic deformation proceeds mainly in narrowly spaced deformation bands, which consist of SFs, dislocations, or twins of nanometer size. ${ }^{[21]}$ Because of a high density of SFs in the deformation bands of the austenite, hexagonal areas are formed, which appear as hcp phase $(\varepsilon$-martensite) in X-ray diffraction experiments or in TEM and EBSD investigations. ${ }^{[22,23]}$

Therefore, a continuous phase transformation sequence $\gamma \rightarrow \varepsilon \rightarrow \alpha^{\prime}$ is often found in this type of steels. Via the $\gamma \rightarrow \varepsilon \rightarrow \alpha^{\prime}$ transformation route, the nucleation of the $\alpha^{\prime}$-martensite needs much less activation energy than the $\gamma \rightarrow \alpha^{\prime}$ route. This is easily explained by considering the involved crystallographic shear operations described in detail by Schumann. ${ }^{[24]}$ Both, the direct $\gamma \rightarrow \alpha^{\prime}$ and the indirect $\gamma \rightarrow \varepsilon \rightarrow \alpha^{\prime}$ transformations start with shearing of the austenite by $1 / 6 a\langle 112\rangle$ ( $a$ is the lattice parameter of the austenite). Through the formation of the hexagonal stacking sequence, this initial shear sequence is automatically produced by the dislocation movement at low SFE, and only the second shear operation needs to be initiated by elastic strains. ${ }^{[24]}$ 
Table I. Chemical Composition of the Investigated Alloy (Optical Emission Spectrometry)

\begin{tabular}{ccccccccc}
\hline & $\mathrm{Fe}$ & $\mathrm{Cr}$ & $\mathrm{Mn}$ & $\mathrm{Ni}$ & $\mathrm{Si}$ & $\mathrm{Al}$ & $\mathrm{C}$ & $\mathrm{N}$ \\
\hline Weight percent & bal. & 15.5 & 6.1 & 6.1 & 0.9 & 0.14 & 0.03 & 0.03 \\
\hline
\end{tabular}

Deformation twinning is observed at SFEs between 20 and $40 \mathrm{~mJ} / \mathrm{m}^{2}$. Because the energy barrier for the $\varepsilon$-martensite formation becomes unfavorable, twinning is observed instead. ${ }^{[25,26]}$ The mechanism of twin formation can be assumed to be similar to that of the $\varepsilon$-martensite formation, which manifests a transition from the less-ordered SF arrangement during the $\varepsilon$-martensite formation toward the highly ordered stacking fault formation on every consecutive $\{111\} \gamma$ lattice plane. ${ }^{[27]}$ Consequently, the $A B C$ stacking order of the austenite is reversed into the $\Sigma 3$ twin orientation. In this way, a high shear strain of 0.707 is produced, which results in large strains until fracture during tensile testing. ${ }^{[28]}$

Depending on the testing temperature, different deformation mechanisms are activated for the investigated material with a SFE of $\sim 17.5 \pm 1.4 \mathrm{~mJ} / \mathrm{m}^{2}$ at room temperature. ${ }^{[29]}$ The deformation mechanisms for the $\mathrm{CrMnNi}$ steel investigated are correlated with the mechanical properties and are summarized in a schema, which involves the deformation temperature and the SFE.

\section{EXPERIMENTAL}

Due to the high costs of nickel as alloying element, it is intended to substitute nickel by cheaper manganese instead. ${ }^{[30]}$ The chemical composition of the investigated material (Table I) is based on a patent specification for maximizing energy absorption by the TRIP effect. ${ }^{[31]}$ The steel alloy was cast into sand dies with dimensions of $200 \times 200 \times 16 \mathrm{~mm}$ by ACTech GmbH, Freiberg, Germany. After machining, the tensile samples with $6 \mathrm{~mm}$ diameter were heat treated at $1323 \mathrm{~K}\left(1050{ }^{\circ} \mathrm{C}\right)$ for 30 minutes and quenched in an argon stream (at room temperature) for homogenization and in order to remove deformation layers or martensitic phase transformations caused by mechanical manufacturing process from the outer surface. For tensile testing with a strain rate of $0.0004 \mathrm{~s}^{-1}$, a servo-hydraulic testing device (Zwick 1476) equipped with a temperature chamber was used. After mechanical testing, the samples were axially dissected and electrolytically polished using a Struers LectroPol-5 with the A3 electrolyte for 3 seconds.

The as-cast material was characterized by a dendritic solidification associated with chemical segregations and a grain size of 100 to $1000 \mu \mathrm{m}$ with a high aspect ratio. Although XRD only shows diffraction maxima referring to the fcc austenite, approximately 2 to 3 vol pct of $\delta$ ferrite can be found in the dendritic areas, as the hightemperature bcc phase is stabilized down to room temperature by the high chromium concentration during the primary ferritic solidification. Neighboring areas are enriched by $\mathrm{Mn}$ and $\mathrm{Ni}$ changing the deformation behavior locally, which in general depends on the chemical composition. As the influence of the individual chemical elements is discussed elsewhere by Jahn et al. ${ }^{[32]}$ the segregation behavior is not the focus of the present paper.

For qualitative and semi-quantitative phase analysis, XRD was carried out in Bragg-Brentano geometry $(20 \leq 2 \theta \leq 150 \mathrm{deg})$ using an RD7 (Seifert/Freiberger Praezisionsmechanik) with $\mathrm{CuK} \alpha$ radiation. A graphite monochromator in front of the scintillation-detector was employed to reduce the fluorescence radiation from iron. Due to the large grain size of the cast material, only a few (though very large) crystallites satisfy the diffraction condition, so that an ideal powder pattern with the expected intensity ratios of the specific hkl reflections could not be obtained. With ongoing deformation and after the martensitic phase transformation, more reflections appeared, but poor statistics were still recognizable. Consequently, a different method was utilized to quantify the phase fraction of martensitic transformation after deformation. The ferromagnetic bcc phase fraction (ferrite $+\alpha^{\prime}$-martensite) could be determined by magnetic measurements, in which the magnetization of the sample in external magnetic fields is measured. Under consideration of the actual sample volume, the magnetic phase fraction can be determined from reference measurements. The benefit of this method lies in the integral measurement over the whole volume of the coarse-grained specimen.

The varying deformation mechanisms were investigated by SEM and EBSD. By using Electron Channeling Contrast Imaging (ECCI), even individual lattice defects like extended stacking faults, deformation twins, or dislocation tangles can be depicted. ${ }^{[33-37]}$ A LEO 1530 Gemini (Carl Zeiss, Oberkochen) operating in high current mode at $20 \mathrm{keV}$ at 5 and $15 \mathrm{~mm}$ working distance was used for ECCI and EBSD, respectively. Channel 5 software (Oxford HKL), served for the processing of the Kikuchi pattern, the phase discrimination, and the orientation determination. The austenite was described by fcc iron, $\alpha^{\prime}$-martensite by bcc iron, and $\varepsilon$-martensite by the hcp high-pressure modification of iron.

\section{RESULTS AND DISCUSSION}

\section{A. Microstructure Investigations of the Deformed Samples}

The temperature dependence of the different deformation mechanisms could be obtained conveniently by comparing the phase composition before and after plastic deformation. Although the steel was mainly austenitic in the as-produced state, $\varepsilon$ - and $\alpha^{\prime}$-martensite could be formed during plastic deformation. The extent of the martensitic transformation during plastic 


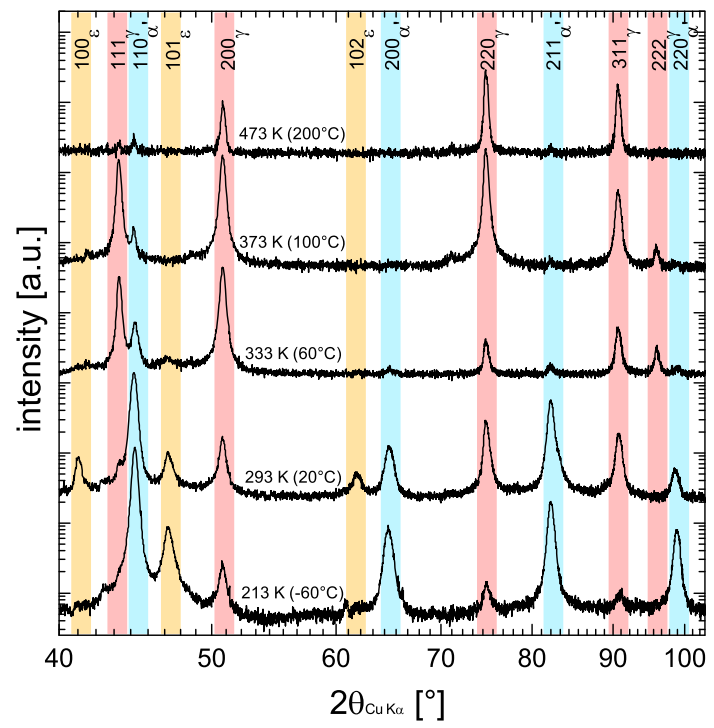

Fig. 2-XRD Diffraction patterns of the TRIP/TWIP steel after plastic deformation until uniform elongation at different testing temperatures. Below $333 \mathrm{~K}\left(60^{\circ} \mathrm{C}\right)$, a pronounced formation of $\alpha^{\prime}$-martensite and $\varepsilon$-martensite was observed, whereas at higher temperatures, the TRIP/TWIP steel remained in the fcc austenite phase.

deformation at different deformation temperatures is shown in Figure 2, which depicts the XRD data of the samples deformed until the end of uniform elongation. At $213 \mathrm{~K}\left(-60{ }^{\circ} \mathrm{C}\right), \alpha^{\prime}$-martensite was the dominant phase after the plastic deformation, and only a small amount of austenite remained. With increasing deformation temperature, the amounts of $\alpha^{\prime}$ - and $\varepsilon$-martensite decreased, which indicated a change in the deformation mechanism during plastic deformation. At temperatures above $333 \mathrm{~K}\left(60{ }^{\circ} \mathrm{C}\right)$, the austenite was the phase that accommodated the main part of the plastic deformation. Consequently, it could be concluded that a decreasing driving force with increasing deformation temperature for the formation of $\alpha^{\prime}$-martensite was active. The intensity of the corresponding diffraction lines of $\alpha^{\prime}$-martensite was always superimposed by the 2 to 3 vol pct of $\delta$-ferrite, which was present in the as-cast state. At $473 \mathrm{~K}\left(200^{\circ} \mathrm{C}\right)$, the intensity of $111_{\gamma}$ was not observed due to the coarse-grained cast state, although it should have comprised the highest intensity.

To reveal and highlight the deformation mechanisms in detail, SEM investigations after reaching uniform elongation and in distinct deformation stages were conducted. In Figure 3, micrographs and EBSD phase maps are displayed which present the characteristics of the specific deformation mechanisms at the individual temperatures. The SEM image (Figure 3(a)) shows deformation bands after 10 pct plastic strain at $213 \mathrm{~K}$ $\left(-60{ }^{\circ} \mathrm{C}\right)$. Individual stacking faults (the red circle in Figure 3(a)) indicate the development of these bands by their continuous growth from stacking faults formed via partial dislocation separation as a consequence of the applied stress. At this specific temperature, the individual stacking faults were particularly wide, because the SFE had the lowest value compared to the other testing temperatures. ${ }^{[38]}$ Consequently, SFs could even be found spanned on secondary glide planes between the deformation bands (arrow), as already observed by Weidner et al. ${ }^{[33]}$ Hardly any dislocation tangles could be observed along the deformation bands. This indicated that due to the low SFE, the critical dissociation stress needed to generate large stacking faults is low as well. If the density of the stacking faults in the deformation bands is high enough, the deformation bands are assigned to hcp iron ( $\varepsilon$-martensite). ${ }^{[22,39]}$ The hcp lattice provides a suitable nucleation environment for $\alpha^{\prime}$-martensite, as only a single crystallographic shear operation is necessary for the phase transformation into the bcc lattice instead of the two-step shear operation from the fcc austenite. ${ }^{[24]}$ Inside the deformation bands, many small $\alpha^{\prime}$-martensite nuclei are formed and not only at crossings of deformation bands, as assumed by Olson and Cohen ${ }^{[40]}$ and Sinclair and Hoagland. ${ }^{[41]}$ These $\alpha^{\prime}$-martensite crystallites grow until they reach the interface of other nuclei, forming larger transformation areas. As the macroscopic strain reaches uniform elongation, nearly the whole volume of the tensile sample was transformed into fine-grained $\alpha^{\prime}$-martensite, as seen in Figure 3(f). Only small 'islands' of austenite remain. This could have been due to two reasons. The first one may be a mechanical shielding by surrounding $\alpha^{\prime}$-martensite, which exhibits higher strength and, therefore, absorbs the load. The second reason may be given through chemical inhomogeneities in terms of higher $\mathrm{Ni}$ and $\mathrm{Mn}$ concentrations, which would lower the driving force for $\alpha^{\prime}$-martensite formation. Further, some large, blocky $\alpha^{\prime}$-martensite grains could be found (black rectangle in Figure 3(f)). This was related to the spontaneous $\alpha^{\prime}$-martensite formation during the 'elastic' deformation at the beginning of the tensile experiment. This 'stress-induced' $\alpha$ '-martensite formed parallel to the slip planes of the austenite, which is described in detail in References 42, 43. As caused by the subsequent plastic deformation of the whole crystalline aggregate, these straight blocks became deformed and appeared bent, as can be seen in Figure 3(f).

At room temperature, the deformation mechanism was similar to the one described above, although no 'stress-induced' $\alpha$-martensite was observed. Hence, the $\alpha^{\prime}$-martensite was formed by plastic deformation of the austenite. In Figure 3(b), it is obvious that most of the stacking faults were confined to the deformation bands, and once again the areas beside the deformation bands did not exhibit a high defect density. Deformation bands were identified as $\varepsilon$-martensite by TEM or EBSD. Quantitative phase analysis yields approx. 20 vol pct of $\varepsilon$-martensite after 20 pet strain. ${ }^{[4]}$ With ongoing plastic deformation, the deformation bands grew in width and further new deformation bands form alongside because the motion of the (partial) dislocations in the initial deformation band was obstructed by the $\alpha^{\prime}$-martensite nuclei. This process continued until the whole grains were filled with deformation bands, which transformed successively into $\alpha^{\prime}$-martensite (Figure 3(g)). ${ }^{[45]}$

Above room temperature, the transformation behavior changed tremendously. The deformation bands with 

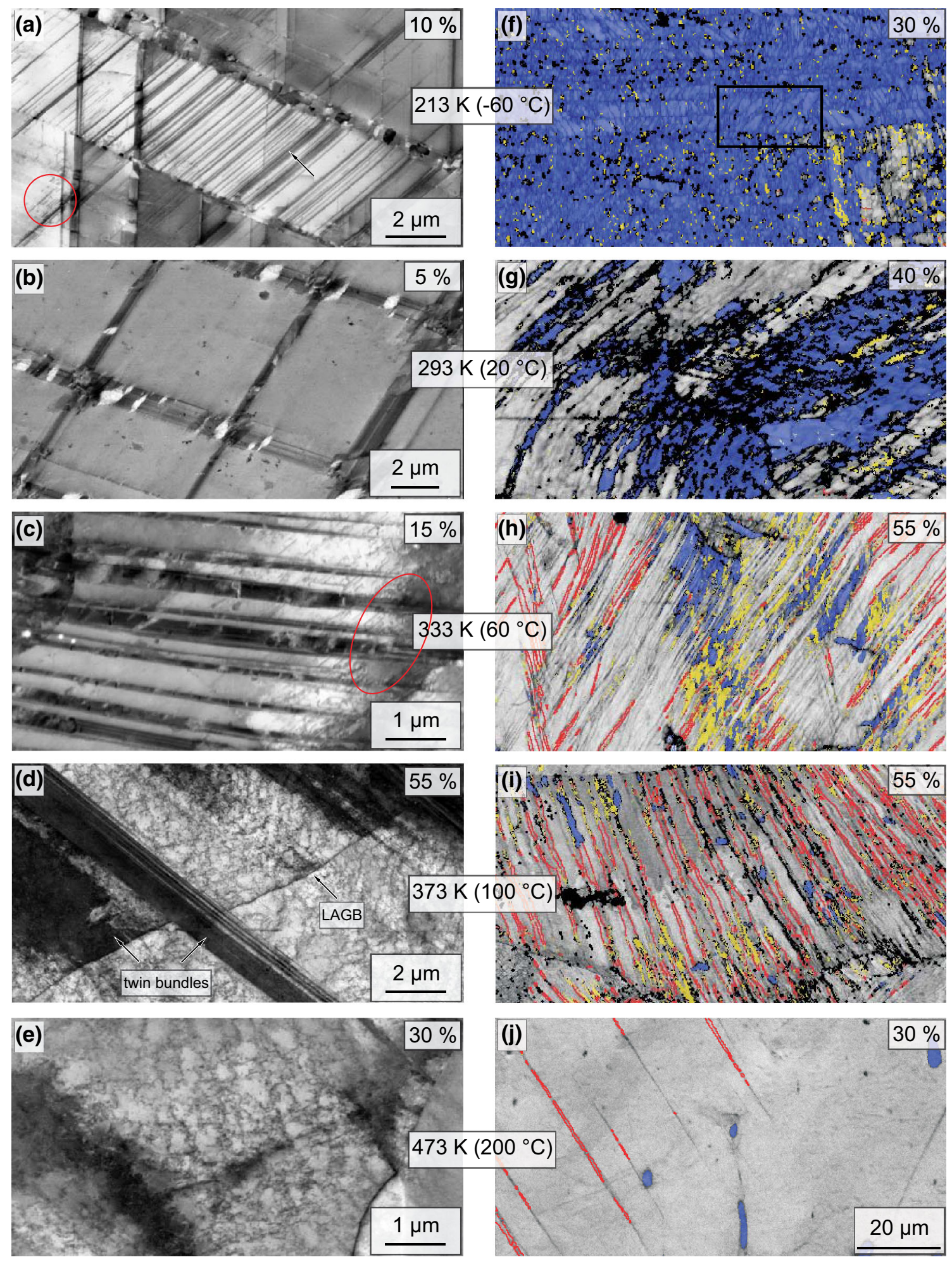

Fig. 3-SEM characterization of the deformation mechanism at different strains and testing temperatures. Left column: inverted ECCI; right column: EBSD phase maps. Gray - austenite (band contrast), yellow- $\varepsilon$-martensite, blue — $\alpha^{\prime}$-martensite, black - not indexed, red lines - fcc, $\Sigma 3$-twin boundaries indicating deformation twins (all EBSD maps $f-j$ share the same scale bar) (Color figure online).

$\alpha^{\prime}$-martensite nuclei were still visible after 15 pct of plastic deformation (Figure 3(c)). The deformation bands originate in the left side of the image and ended in an area where many dislocations were piled up (red circle). In contrast to the previously described deformation temperatures, conventional motion of regular dislocations (or, rather, the movement of partials, where the dissociation width is not large enough to 
prevent cross slip) seemed to play an important role. As the critical stress for the 'infinitely' wide partial dislocation separation was much higher at these temperatures due to the increased SFE, ${ }^{[18]}$ much more dislocation motion was activated before band formation was observed. Thus, a lattice curvature could form 'bent' deformation bands (Figure 3(c)). Defect agglomerations like dislocation pile-ups acted as barriers for the (partial) dislocation motion, stopping the deformation bands. ${ }^{[46]}$ It could not be distinguished from the SEM images whether the bands contained $\varepsilon$-martensite or twins of the austenite. However, the EBSD measurement clearly showed the occurrence of both phenomena after 55 pct of plastic deformation at $333 \mathrm{~K}\left(60^{\circ} \mathrm{C}\right)$ in Figure $3(\mathrm{~h})$. The continuous transition between both phenomena in some deformation bands underlines the assumption that the stacking fault arrangement decides the character of the deformation band. Either a more or less regular stacking on every second $\{111\}$ austenite lattice of the active slip plane creates the $\varepsilon$-martensite, or a successive stacking of faults on every $\{111\}$ plane results in the coherent twin orientation. ${ }^{[6,10]}$

When the testing temperature was further increased, the predominant deformation mechanism shifted toward twinning. In the SEM image (Figure 3(d)), closely spaced twin lamellae are observed. In addition to the twin packages, dislocations and dislocation tangles represent the most pronounced microstructural feature. If dislocation tangles are observed, 'cross slip' must be an active mechanism. ${ }^{[47]}$ Obviously, the increased SFE at $373 \mathrm{~K}\left(100{ }^{\circ} \mathrm{C}\right)$ enables a recombination of the partial dislocations if the leading partial dislocation is decelerated by the stress fields from the obstacles. ${ }^{[48]}$ Figure 3(d) shows further that during twin growth even low-angle grain boundaries (LAGB) could be overcome. This reflects the fact that bent twins can be observed in the deformation microstructures as LAGBs, and lattice curvature from prior dislocation slip can be accommodated during twin growth by partial dislocation movement. ${ }^{[49]}$ As the individual twin lamellae could not be resolved, the whole twin bundles were identified as one uniform twin orientation. In Figure 3(i), only the outer interface of the twin bundle with the austenitic matrix is depicted by red lines. Further yellow pixels indicate $\varepsilon$-martensite, which means that there is no strictly periodic arrangement of the stacking faults. So faulted austenite, faulted hexagonal $\varepsilon$-martensite, twins, and transitional states coexist in the deformation bands. Even some $\alpha^{\prime}$-martensite can be found, but the total amount does not exceed 5 vol pct after reaching uniform elongation.

At $473 \mathrm{~K}\left(200{ }^{\circ} \mathrm{C}\right)$, the plasticity is mainly driven by dislocation slip. The corresponding dislocations, the dislocation tangles, and their interaction with grain boundaries are depicted in Figure 3(e). Only some twin bundles are detected in the EBSD phase mapping (Figure 3(j)). No $\alpha^{\prime}$-martensite could be detected and all bcc grains contained $\delta$-ferrite from the as-cast state. Obviously, the deformation mechanisms as well as the dislocation slip decline above the $473 \mathrm{~K}\left(200^{\circ} \mathrm{C}\right)$ testing temperature.

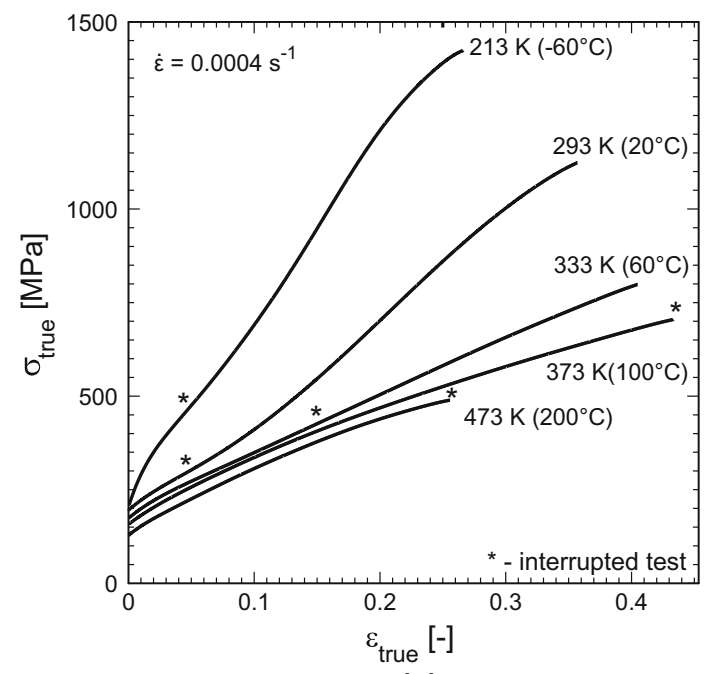

(a)

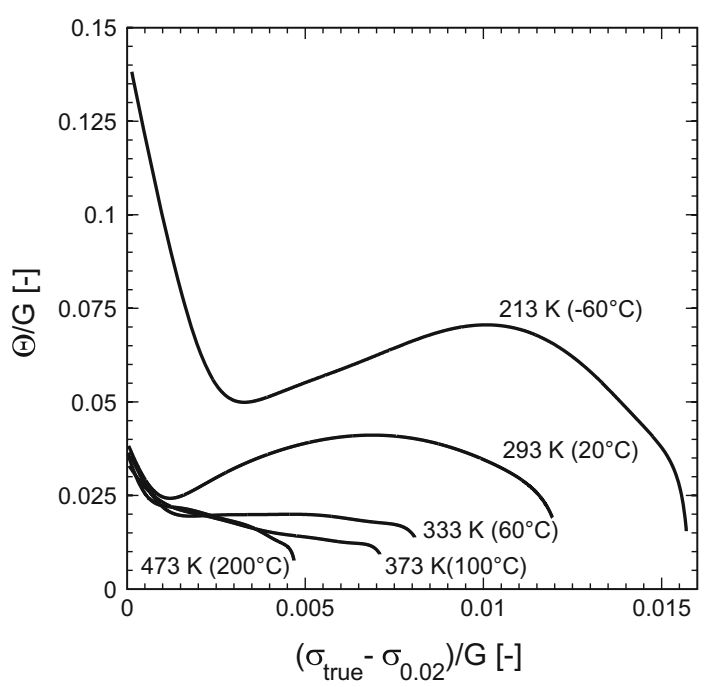

(b)

Fig. 4-Mechanical properties determined from tensile tests at different testing temperatures of the CrMnNi-TRIP/TWIP steel: (a) flow curves, (b) Kocks-Mecking Plot: work-hardening rate plotted vs true stress normalized by the shear modulus. The asterisks mark the deformations in the samples, which were used for the microstructure analysis using SEM, EBSD, ECCI, and XRD.

\section{B. Correlation with the Mechanical Properties}

The different deformation mechanisms cause completely different work-hardening behavior and varying maximal strains during tensile testing (Figure 4). The highest ultimate tensile strength (UTS) value of nearly $1500 \mathrm{MPa}$ was observed at $213 \mathrm{~K}\left(-60^{\circ} \mathrm{C}\right)$. Tensile strength decreased with increasing testing temperature (Figure 4(a)). The tensile strain at the end of the uniform elongation exhibited a maximum at $373 \mathrm{~K}$ $\left(100{ }^{\circ} \mathrm{C}\right)$, whereas the lowest strength and elongation were recorded at $473 \mathrm{~K}\left(200{ }^{\circ} \mathrm{C}\right)$. The characteristics of the work hardening change drastically with the testing temperatures (Figure 4(b)). The initial decline of the work hardening in all graphs from Figure 4(b) represents the usual behavior of fcc metals. ${ }^{[50]}$ Still, the much 
higher work hardening at $213 \mathrm{~K}\left(-60^{\circ} \mathrm{C}\right)$ could be attributed to the martensitic transformation prior to the deformation and at the beginning of the deformation process. A higher phase fraction of $\alpha^{\prime}$-martensite could be found already at the beginning of the mechanical experiments, as the testing temperature was situated below the $M_{\mathrm{s}}$ temperature. ${ }^{[32]}$ Therefore, the athermal $\alpha^{\prime}$-martensite ( $\left.\leq 10 \mathrm{vol} \mathrm{pct}\right)$ was formed during cooling of the sample from room temperature down to $213 \mathrm{~K}$ $\left(-60{ }^{\circ} \mathrm{C}\right)$. Due to the sigmoidal shape of the stressstrain curves, the work-hardening rates observed at the testing temperatures of $213 \mathrm{~K}$ and $293 \mathrm{~K}\left(-60{ }^{\circ} \mathrm{C}\right.$ and $20{ }^{\circ} \mathrm{C}$ ) show an increase and a maximum of hardening during the plastic deformation, which is known to be attributed to the deformation-induced $\alpha^{\prime}$-martensite formation. ${ }^{[3]}$ But the yield strength of $\alpha^{\prime}$-martensite is probably not that high, as the concentration of interstitial elements is rather low. Weidner et al. ${ }^{[51]}$ reported that the nano-hardness of the $\alpha^{\prime}$-martensite is not much higher than the surrounding austenite. The continuously evolving $\alpha^{\prime}$-martensite nuclei shorten the mean free path of the (partial) dislocations in the deformation bands in the 'single slip mode' (compare Figure 3(b)). The martensitic nuclei create new interfaces that act as hard obstacles to the dislocation motion. ${ }^{[52]}$ With increasing testing temperature, the work hardening decreases. At $293 \mathrm{~K}$ and $373 \mathrm{~K}\left(60{ }^{\circ} \mathrm{C}\right.$ and $\left.100{ }^{\circ} \mathrm{C}\right)$, the expanded region with a nearly constant value of the strain hardening is dominated by twinning as the deformation mechanism in low SFE alloys. ${ }^{[53]}$ This reduced workhardening capability (as compared to the $\alpha^{\prime}$-martensite formation) is due to the fact that the Burgers vector of the dislocations moving in the deformation band is parallel to the partial dislocations, which form the twinned region in the same deformation band. ${ }^{[20]}$ Only after activation of twinning on the secondary glide system, a more pronounced hardening effect is observed. ${ }^{[54,55]}$

When the data of the tensile tests were complemented by further testing temperatures, ${ }^{[56,57]}$ the dependence of the mechanical parameters on the testing temperature could be obtained (Figure 5). The yield strength $\left(\mathrm{YS} \triangleq \sigma_{0.02}\right.$, Figure 5(a)) decreases with increasing testing temperature as a consequence of the thermal activation of the dislocation motion. ${ }^{[50]}$ A drop of the yield strength between $293 \mathrm{~K}$ and $203 \mathrm{~K}\left(20^{\circ} \mathrm{C}\right.$ and $-70{ }^{\circ} \mathrm{C}$ ) is associated with stress-induced $\alpha^{\prime}$-martensite formation during the elastic deformation of the austenite. As the phase transformation is accompanied by an increase of the specific volume $\left(\Delta V \approx 2.3 \mathrm{pct}^{[22]}\right)$, a directional elongation of the tensile sample in the direction of loading is achieved spontaneously, resulting in a drop in the measured stress. ${ }^{[42]}$ The increase of YS at temperatures below $213 \mathrm{~K}\left(-60{ }^{\circ} \mathrm{C}\right)$ could be explained by the athermal $\alpha^{\prime}$-martensite formation ( $\sim 10$ vol pct) during cooling of the sample down to the testing temperature. Consequently, a higher amount of interfacial area is created in the large austenitic grains, and the external load is distributed to the volume fractions of austenite and $\alpha^{\prime}$-martensite.

The ultimate tensile strength increased with decreasing deformation temperature; the increase was propor-

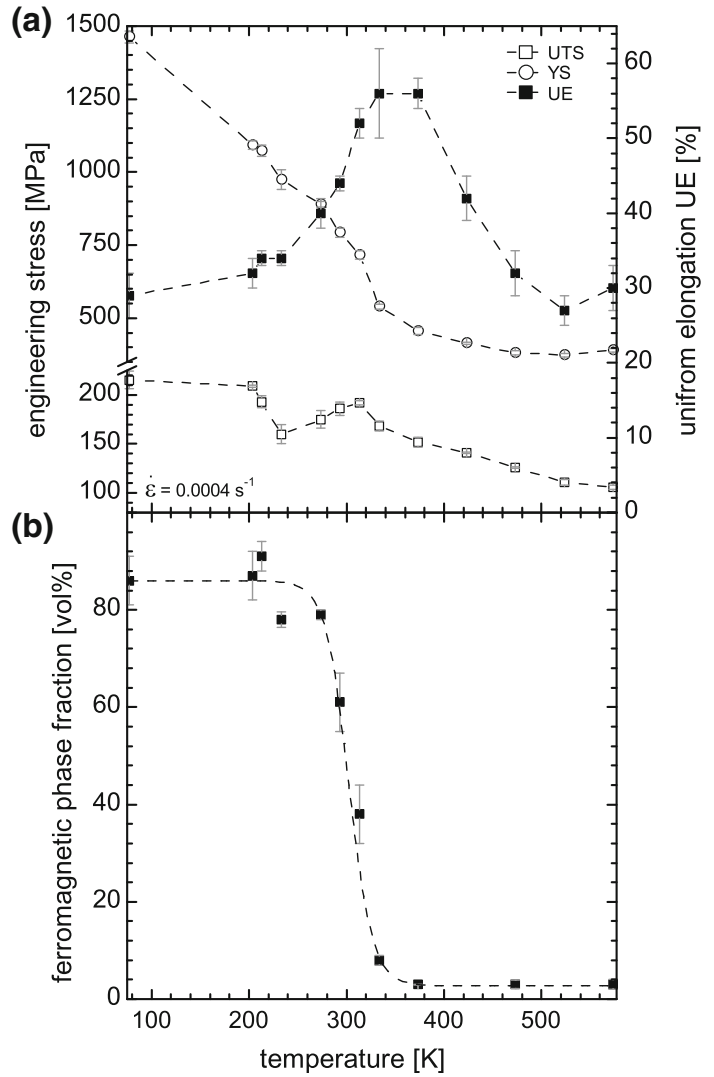

Fig. 5-Parameters of the CrMnNi-TRIP/TWIP steel obtained from the tensile tests performed at different testing temperatures ( $c f$. Fig. 3): (a) YS-Yield strength $\triangleq \sigma 0.02$, UTS-Ultimate tensile strength, UE-Uniform Elongation; (b) ferromagnetic phase fraction after testing until UE (additional data compared to Fig. 3 taken from Refs. [56,57]).

tional to the amount of $\alpha^{\prime}$-martensite formed between $200 \mathrm{~K}$ and $573 \mathrm{~K}\left(-70{ }^{\circ} \mathrm{C}\right.$ and $\left.300{ }^{\circ} \mathrm{C}\right)$ (Figure $5(\mathrm{~b})$ ). Remarkably, the UTS increased between $293 \mathrm{~K}$ and $333 \mathrm{~K} \quad\left(20^{\circ} \mathrm{C}\right.$ and $\left.60^{\circ} \mathrm{C}\right)$ when the amount of $\alpha^{\prime}$-martensite increased tremendously (see Figures $3(\mathrm{~g}$ ) and (h)). The ultimate elongation reached a maximum between $213 \mathrm{~K}$ and $473 \mathrm{~K}\left(-60{ }^{\circ} \mathrm{C}\right.$ and $\left.200{ }^{\circ} \mathrm{C}\right)$. The TRIP effect could only be attributed to the left part of the maximum, as $\alpha^{\prime}$-martensite was formed in sufficient amounts to influence the plastic deformation behavior below $373 \mathrm{~K} \quad\left(100{ }^{\circ} \mathrm{C}\right)$. The excellent deformation behavior through the TRIP effect is often dedicated to a delayed fracture due to the pronounced work hardening of the severely deformed grains, which dissipate the strain into neighboring grains. ${ }^{[58]}$

However, another aspect needs to be taken into account if the ductility of the sample is to be discussed. The transformation of the $\alpha^{\prime}$-martensite proceeds within the deformation bands, which exhibit a high SF density. Assuming a perfect hexagonal stacking order produced by the SFs, a shear strain of approx. 0.35 is achieved that resembles half the amount of twinning (Figure 6). At around 20 pet strain at room temperature, approx. 20 vol pct of $\varepsilon$-martensite can be quantified using XRD. ${ }^{[4]}$ Due to the fact that $\varepsilon$-martensite is consumed by $\alpha^{\prime}$-martensite formation, a much higher cumulative 


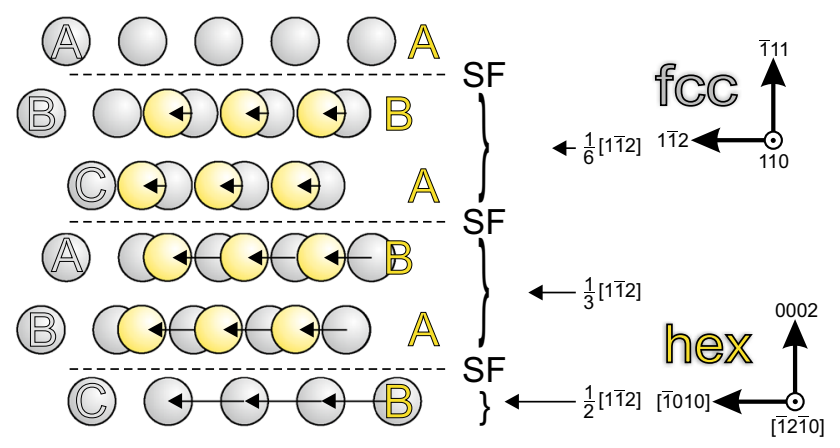

(a)

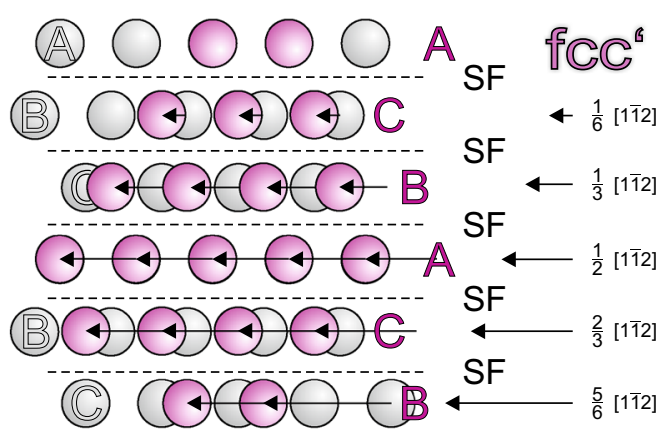

(b)

Fig. 6 - Comparison of the formation of $\varepsilon$-martensite and twins by successive arrangement of SFs via the Shockley partial dislocation movement. The model was constructed from EBSD orientation data of the primary slip system in Fig. 2(h). The $\varepsilon$-martensite was formed by a regular arrangement of SFs on every second (111) plane. (a), the twinned orientation (fcc') was achieved by shearing the matrix on every (111) plane. (b) The cumulative amount of shear and the direction for every SF are indicated with respect to the top layer of atoms. Gray balls represent the atomic positions in austenite, yellow balls the atomic positions in $\varepsilon$-martensite and purple balls twinned orientation (Color figure online).

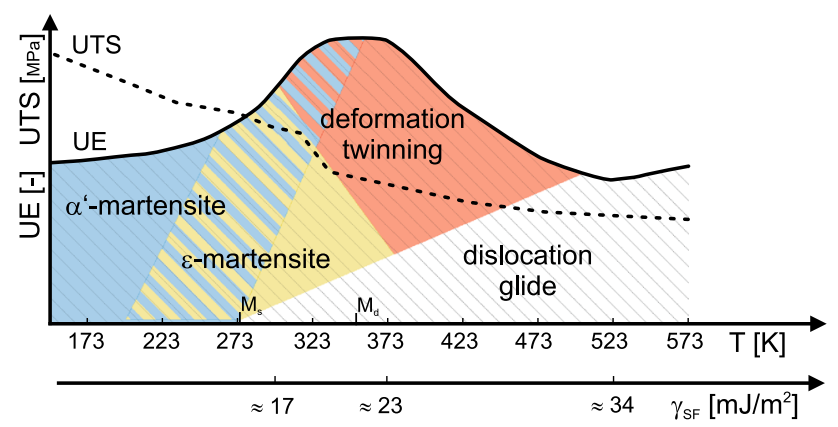

Fig. 7-Schematic overview of the activated deformation mechanisms as a function of testing temperature in correlation with the SFE and the mechanical properties of the CrMnNi TRIP/TWIP steel.

amount of $\varepsilon$-martensite can be assumed during plastic deformation. It is proposed that a distinctive contribution of the increased ultimate elongation values in the 'TRIP regime' is dedicated to $\varepsilon$-martensite formation. The highest ultimate elongation at $373 \mathrm{~K}\left(100{ }^{\circ} \mathrm{C}\right)$ and the right side of the maximum of the uniform elongation are clearly due to the deformation-induced twinning and the TWIP effect, ${ }^{[59,60]}$ as only small phase fractions ( $\leq 5 \mathrm{vol}$ pct) of $\varepsilon$-martensite and $\alpha^{\prime}$-martensite are formed.

\section{Transition of the Deformation Mechanisms}

From the presented microstructural investigations and from additional interrupted deformation tests performed at various temperatures (reported in References 39, 44, 45), a scheme was developed that included all the observed deformation mechanisms (see Figure 7). The deformation mechanisms were correlated with the mechanical properties and the SFE. The SFE of the CrMnNi TRIP steel investigated was determined to be $17.5 \pm 1.4 \mathrm{~mJ} / \mathrm{m}^{2}$ at room temperature by Rafaja et al. ${ }^{[29]}$ The SFE can be extrapolated to higher temperatures assuming an average increase of the SFE with temperature of $0.075 \mathrm{~mJ} / \mathrm{Km}^{2}{ }^{[61]}$ The basis of all deformation mechanisms is dislocation movement, which is altered significantly by the varying SFE at different testing temperatures. At low strains, in general, and at high deformation temperatures $(\geq 473 \mathrm{~K}$ $\left(200{ }^{\circ} \mathrm{C}\right)$ ), only dislocation slip is observed. As the formation of large stacking faults depends on the stress that is applied on the partial dislocations, ${ }^{[18]}$ the separation width of the partials is too low to produce recognizable SFs at low strains. At higher temperatures, the SFE is too high, such that it can be compensated by the applied stress to achieve an infinite partial dislocation separation. At temperatures below $473 \mathrm{~K}\left(200{ }^{\circ} \mathrm{C}\right)$, a pronounced SF formation can be observed. The arrangement of the SFs is controlled by $\Delta G^{\gamma \rightarrow \varepsilon}$, which is the main contribution for the calculation of the SFE and exhibits a strong dependence on temperature. ${ }^{[6]}$

If the energy difference between the fcc and hcp structure is close to zero or even negative, ${ }^{[6]}$ the $\varepsilon$-martensite formation due to the high density of SFs in the deformation bands can be observed. At temperatures exceeding room temperature, the SFE and $\Delta G^{\gamma \rightarrow \varepsilon}$ increase and the separation width of the partial dislocations decreases. The hexagonal stacking sequence becomes thermodynamically unfavorable. Consequently, hcp stacking is omitted and the SFs are ordered more closely, with every consecutive lattice plane forming twins in the deformation bands of the austenite. ${ }^{[1]}$ Then only the SFs bordering the austenitic twins form an hcp stacking sequence of four lattice planes. ${ }^{[10]}$ Thus, the microstructural features such as $\varepsilon$-martensite and twins are produced locally by a distinct geometrical arrangement of the SFs. In the investigated steel, the term $\Delta G^{\gamma \rightarrow \varepsilon}$ represents the key term which decides whether $\varepsilon$-martensite or twins are formed. ${ }^{[10]}$ A specific SFE threshold for the onset of different deformation mechanisms cannot be concluded, as a continuous transition between particular deformation mechanisms as a function of temperature and applied strain was observed. Nevertheless, the reported SFEs between 18 and $40 \mathrm{~mJ} / \mathrm{m}^{2}$ were validated to facilitate the deformation twinning in austenitic CrMnNi steels. ${ }^{[25,26,62]}$

At temperatures below $333 \mathrm{~K}\left(60^{\circ} \mathrm{C}\right), \alpha^{\prime}$-martensite is formed during plastic deformation. With the onset of 
the transformation into the bcc phase, work hardening is significantly increased and higher stress levels are observed. The $\alpha^{\prime}$-martensite evolves primarily after a high SF density has formed in the deformation bands, because the $\varepsilon$-martensite provides the best nucleation sites. By the local shearing of the austenitic matrix by the SFs, the two-step transformation process from fcc to bcc is simplified to a single shear operation, lowering the activation energy of the martensitic phase transformation. ${ }^{[2]}$ By means of plastic deformation, the nucleation sites for the martensitic phase transformation are produced. Through the influence of the low stacking fault energy, the $\gamma \rightarrow \varepsilon \rightarrow \alpha^{\prime}$ transformation is triggered. Below room temperature, the thermodynamic driving force for the $\alpha^{\prime}$-martensite formation was increased. Thus, no intermediate $\varepsilon$-martensite was needed, and a direct transformation $\gamma \rightarrow \alpha^{\prime}$ was observed.

\section{CONCLUSIONS}

High-alloy CrMnNi austenitic TRIP/TWIP steel was deformed at temperatures between $213 \mathrm{~K}$ and $473 \mathrm{~K}$ $\left(-60{ }^{\circ} \mathrm{C}\right.$ and $200{ }^{\circ} \mathrm{C}$ ) by quasi-static tensile testing. The highest strength was measured at $213 \mathrm{~K}\left(-60{ }^{\circ} \mathrm{C}\right)$, whereas the highest elongation was detected at $373 \mathrm{~K}$ $\left(100{ }^{\circ} \mathrm{C}\right)$. Microstructural investigations showed a pronounced $\alpha^{\prime}$-martensite formation at low temperatures and a transition via $\varepsilon$-martensite to mechanical twinning at higher temperatures. A continuous transition from the TRIP to the TWIP effect was observed. The evolution of the maximum elongation of the TRIP/ TWIP steel was shown to be related to the change in the deformation mechanism. Dislocation motion under circumstances of low stacking fault energy generated large stacking faults. The SFE controlled the alignment of the SFs during plastic deformation. The formation of $\varepsilon$-martensite at the temperatures between $213 \mathrm{~K}$ and $373 \mathrm{~K}\left(-60{ }^{\circ} \mathrm{C}\right.$ and $\left.100^{\circ} \mathrm{C}\right)$ and the formation of twins between $293 \mathrm{~K}$ and $523 \mathrm{~K}\left(20^{\circ} \mathrm{C}\right.$ and $\left.250{ }^{\circ} \mathrm{C}\right)$ were observed. Twinning was observed in the temperature range where the SFE was between 17 and $35 \mathrm{~mJ} / \mathrm{m}^{2}$. The formation of twins at higher testing temperatures and higher SFE values can be explained by a negligible contribution of the term $\Delta G^{\gamma \rightarrow \varepsilon}$, when the sheared volume retains the fcc structure. A scheme was presented assigning temperature and SFE values to the active deformation mechanisms. From this scheme, the effect of the changing deformation mechanisms on the mechanical properties could be derived.

\section{ACKNOWLEDGMENTS}

This work was financially supported by the German Research Foundation (DFG) within the framework of the collaborative research center SFB 799 'TRIPmatrix composites.' The authors wish to thank the Institute of Iron and Steel Technology (TU Bergakademie
Freiberg) for the magnetic measurements and the chemical analysis.

\section{REFERENCES}

1. J. Breedis and L. Kaufman: Metall. Trans., 1971, vol. 2, pp. 2359-71.

2. V. Zackay, E. Parker, D. Fahr, and R. Busch: Trans. Am. Soc. Metals, 1967, vol. 60, pp. 252-59.

3. Y. Tomita and T. Iwamoto: Int. J. Mech. Sci., 1995, vol. 37, pp. 1295-1305.

4. J. Patel and M. Cohen: Acta Metall. Mater., 1953, vol. 1, pp. 531-38.

5. L. Kaufmann and M. Cohen: Prog. Met. Phys., 1958, vol. 7, pp. 165-246.

6. G. Olson and M. Cohen: Metall. Trans. A, 1976, vol. 7A, pp. 1897-1904.

7. J. Nakano and P. Jacques: CALPHAD, 2010, vol. 34, pp. 167-75.

8. R. Schramm and R. Reed: Metall. Trans. A, 1975, vol. 6A, pp. $1345-51$.

9. P. Müllner and P. Ferreira: Philos. Mag. Lett., 1996, vol. 73, pp. 289-97.

10. D. Geissler, J. Freudenberger, A. Kaumann, S. Martin, and D. Rafaja: Philos. Mag., 2014, vol. 94, pp. 2967-79.

11. F. Lecroisey and A. Pineau: Metall. Trans. A, 1972, vol. 3A, pp. 387-96.

12. A. De, J. Speer, D. Matlock, D. Murdock, M. Mataya, and R. Comstock: Metall. Mater. Trans. A, 2006, vol. 37A, pp. 1875-86.

13. T. Byun, N. Hashimoto, and K. Farrell: J. Nucl. Mater., 2006, vol. 351, pp. 303-15.

14. A. Hamada, L. Karjalainen, R. Misra, and J. Talonen: Mater. Sci. Eng. A, 2013, vol. 559, pp. 336-44.

15. H. Barman, A. Hamada, T. Sahu, B. Mahato, J. Talonen, S. Shee, P. Sahu, D. Porter, and L. Karjalainen: Metall. Mater. Trans. A, 2014, vol. 45A, pp. 1937-52.

16. S. Lee and B. De Cooman: Metall. Mater. Trans. A, 2014, vol. $45 \mathrm{~A}$, pp. $710-16$.

17. M. Linderov, C. Segel, A. Weidner, H. Biermann, and A. Vinogradov: Mater. Sci. Eng. A, 2014, vol. 597, pp. 183-93.

18. T. Byun: Acta Mater., 2003, vol. 51, pp. 3063-71.

19. A. Chen, H. Ruan, J. Wang, H. Chan, Q. Wang, Q. Li, and J. Lu: Acta Mater., 2011, vol. 59, pp. 3697-3709.

20. D. Geissler, J. Freudenberger, A. Kauffmann, M. Krautz, H. Klauss, A. Voss, J. Eickemeyer, and L. Schultz: Acta Mater., 2011, vol. 59, pp. 7711-23.

21. J. Talonen and H. Hänninen: Acta Mater., 2007, vol. 55, pp. 610818.

22. S. Martin, C. Ullrich, D. Šimek, U. Martin, and D. Rafaja: J. Appl. Cryst., 2011, vol. 44, pp. 779-87.

23. D. Borisova, V. Klemm, S. Martin, S. Wolf, and D. Rafaja: Adv. Eng. Mater., 2013, vol. 15, pp. 571-82.

24. H. Schumann: Krist. Technol., 1975, vol. 10, pp. 401-11.

25. K. Sato, M. Ichinose, Y. Hirotsu, and Y. Inoue: ISIJ Int., 1989, vol. 29, pp. 868-77.

26. L. Remy and A. Pineau: Mater. Sci. Eng. A, 1976, vol. 26, pp. 123-32.

27. S. Wu, H. Yen, M. Huang, and A. Ngan: Scripta Mater., 2012, vol. 67, pp. 641-44.

28. O. Grässel, L. Krüger, G. Frommeyer, and L. Meyer: Int. J. Plast., 2000, vol. 16, pp. 1391-1409.

29. D. Rafaja, C. Krbetschek, C. Ullrich, and S. Martin: J. Appl. Cryst., 2014, vol. 47, pp. 936-47.

30. M. Wendler, J. Mola, L. Krüger, and A. Weiß: Steel Res. Int., 2014, vol. 85, pp. 803-10.

31. A. Weiß, H. Gutte, M. Radtke, and P. Scheller: International Patent, 2008, PCT WO2008/009722 A1

32. A. Jahn, A. Kovalev, A. Weiß, and P.R. Scheller: Steel Res. Int., 2011, vol. 82, pp. 1108-12.

33. A. Weidner, S. Martin, V. Klemm, U. Martin, and H. Biermann: Scripta Mater., 2011, vol. 64, pp. 513-16.

34. A. Wilkinson, R. Anstis, J. Czernuszka, N. Long, and P. Hirsch: Philos. Mag., 1993, vol. 68, pp. 59-80. 
35. I. Gutierrez-Urrutia, S. Zaefferer, and D. Raabe: Scripta Mater., 2009, vol. 61, pp. 737-40.

36. I. Gutierrez-Urrutia, S. Zaefferer, and D. Raabe: Jom-J. MET, 2013, vol. 65, pp. 1229-36.

37. S. Zaefferer and N. Elhami: Acta Mater., 2014, vol. 75, pp. 20-50.

38. F. Lecroisey and B. Thomas: Phys. Stat. Sol. A, 1970, vol. 2, pp. K217-19.

39. S. Martin, S. Wolf, L. Krüger, and U. Martin: Conference Proceedings of 8th ESOMAT 2009, Prague, 2009, 05022. DOI: 10.1051/esomat/200905022.

40. G. Olson and M. Cohen: J. Less-Common Met., 1972, vol. 28, pp. $107-18$.

41. C. Sinclair and R. Hoagland: Acta Mater., 2008, vol. 56, pp. 4160-71.

42. D. Bhandarkar, V. Zackay, and E. Parker: Metall. Trans. A, 1972, vol. 3A, pp. 2619-31.

43. R. Naraghi, P. Hedström, and A. Borgenstam: Steel Res. Int., 2011, vol. 82, pp. 337-45.

44. S. Martin, S. Decker, L. Krüger, U. Martin, and D. Rafaja: $A d v$. Eng. Mater., 2013, vol. 15, pp. 600-08.

45. H. Biermann, J. Solarek, and A. Weidner: Steel Res. Int., 2012, vol. 83 , pp. $512-20$.

46. J. Putaux and J. Chevalier: Acta Mater., 1996, vol. 44, pp. 1701-16.

47. I. Gutierrez-Urrutia and D. Raabe: Acta Mater., 2011, vol. 59, pp. 6449-62.

48. H. Wilsdorf and J. Schmitz: J. Appl. Phys., 1962, vol. 33, pp. $1750-54$.
49. A. Albou, M. Galceran, K. Renard, S. Godet, and P. Jacques: Scripta Mater., 2013, vol. 68, pp. 400-03.

50. U. Kocks and H. Mecking: Prog. Mater. Sci., 2003, vol. 48, pp. 171-273.

51. A. Weidner, U. Hangen, and H. Biermann: Philos. Mag. Lett., 2014, vol. 8, pp. 522-30.

52. S. Lee, Y. Estrin, and B. De Cooman: Metall. Mater. Trans. A, 2014, vol. 45A, pp. 717-30.

53. S. Asgari, E. El-Danaf, S. Kalidindi, and R. Doherty: Metall. Mater. Trans. A, 1997, vol. 28A, pp. 1781-95.

54. L. Remy: Metall. Trans. A, 1981, vol. 12, pp. 387-408.

55. D. Steinmetz, T. Jäpel, B. Wietbrock, P. Eisenlohr, I. GutierrezUrrutia, A. Saeed-Akbari, T. Hickel, F. Roters, and D. Raabe: Acta Mater., 2013, vol. 61, pp. 494-510.

56. L. Krüger, S. Wolf, U. Martin, S. Martin, P. Scheller, A. Jahn, and A. Weiß: J. Phys. Conf. Ser., 2010, vol. 240, p. 012098.

57. S. Wolf: Ph.D. Thesis, TU Bergakademie Freiberg, Shaker Verlag, Aachen, 2012.

58. H. Oettel and U. Martin: J. Mater. Res., 2006, vol. 12, pp. $1642-47$.

59. G. Frommeyer, U. Brüx, and P. Neumann: ISIJ Int., 2003, vol. 43, pp. $438-46$.

60. M. Pozuelo, J. Wittig, J. Jiménez, and G. Frommeyer: Metall. Mater. Trans. A, 2009, vol. 40A, pp. 1826-34.

61. L. Remy: Acta Metall. Mater., 1977, vol. 25, pp. 173-79.

62. S. Allain, J.-P. Chateau, O. Bouaziz, S. Migot, and N. Guelton: Mater. Sci. Eng. A, 2004, vols. 387-389, pp. 158-62.

63. L. Remy and A. Pineau: Mater. Sci. Eng., 1978, vol. 36, pp. 47-63. 